\title{
Pheochromocytoma, diagnosis and treatment: Review of the literature
}

\author{
Farrugia FA, Martikos G, Tzanetis P, Charalampopoulos A, \\ Misiakos E, Zavras N, Sotiropoulos D \\ $3^{\text {rd }}$ University Department of Surgery, Attikon University Hospital, University of Athens \\ School of Medicine, Athens, Greece \\ E-mail:farrugiafa@gmail.com
}

Objective. We conducted an extensive review of the literature and tried to cite the most recent recommendations concerning the pheochromocytoma (PHEO).

Methods. Pub Med and Google Scholar databases were searched systematically for studies concerning pheochromocytomas (intra-adrenal paragangliomas) from 1980 until 2016. Bibliographies were searched to find additional articles.

Results. More than four times elevation of plasma fractionated metanephrines or elevated 24-h urinary fractionated metanephrines are keys to diagnosing pheochromocytoma. If the results are equivocal then we perform the clonidine test. If we have not done it already, we preferably do a CT scan and/or an MRI scan. The patient needs pre-treatment with al-blockers at least 10-14 days before operation. Alternatives or sometimes adjuncts are Calcium Channels Blockers and/ or $\beta$-Blockers. Several familial syndromes are associated with $\mathrm{PHEO}$ and genetic testing should be considered.

Conclusions. The biggest problem for pheochromocytoma is to suspect it in the first place. Elevated metanephrines establish the diagnosis. With the proper preoperative preparation the risks during operation and the postoperative period are minimal. If there is a risk of the hereditable mutation, it is strongly suggested that all the patients with pheochromocytoma need clinical genetic testing.

Key words: pheochromocytoma, intra-adrenal paraganglioma, guidelines, diagnosis, radiology, treatment

Pheochromocytomas (PHEOs) and extra adrenal paragangliomas (EAP) are neural crest cell tumors associated with catecholamine production and assessed by a metanephrine measurement (Pacak and Wimalawansa 2015). PHEOs and EAPs and parasympathetic paragangliomas are neuroendocrine tumors derived from the adrenal chromaffin cells or similar cells in extra-adrenal sympathetic and parasympathetic paraganglia, respectively (Chen et al. 2010).

In 2004, the WHO defined PHEOs as an intraadrenal paragangliomas, highlighting the common origin of PHEOs and sympathetic or parasympa- thetic paragangliomas, which are all derived from neuroectoderm and can all occur in patients with the same genetic predisposition (IARC 2004; Pacak et al. 2007). In this study, we shall use the term pheochromocytoma instead of the new term, to avoid any confusion since the old term is still in use worldwide.

\section{Epidemiology}

The estimated incidence of PHEOs ranges from $0.005 \%$ to $0.1 \%$ of the general population and from $0.1 \%$ to $0.2 \%$ of the adult hypertensive population

Corresponding author: Dr. Farrugia FA, 3rd University Department of Surgery, Attikon University Hospital, University of Athens School of Medicine, Athens, Greece; e-mail: farrugiafa@gmail.com 
(Pederson and Lee 2003; Mittendorf et al. 2007). However, this probably accounts for only $50 \%$ of people harboring PHEO because about half the patients with PHEO have paroxysmal hypertension or normotension. The prevalence of PHEO and EAP can be estimated to be between 1:6500 and 1:2500 with the annual incidence in the US of 500 to 1600 cases per year (Chen et al. 2010).

PHEO occurs most frequently in individuals aged $40-50$ years, with a slight predilection in females (55.2\%) than men (44.8\%) (Lenders et al. 2005; Adas et al. 2016).

The rarity and variability render these tumors very difficult to diagnose so that many of them are discovered incidentally during radiological examinations, especially of the abdomen, as adrenal incidentalomas or at autopsy (Bittar 1982; Stenstrom and Svardsudd 1986; Mannelli et al. 1999).

In an "Italian survey", Mantero et al. (2000) studied 1004 cases of adrenal incidentalomas (AI) and 42 (11\%) of which were PHEOs.

\section{Nosology ${ }^{1}$}

The key to diagnosing PHEO is the first to think of it! Since this deceptive tumor poses great risk of death or severe complications, early diagnosis and prompt treatment of this "pharmacologic bomb" are crucial (Manger and Gifford 2002). Because it secretes catecholamines, often episodically, PHEO frequently presents dramatically and explosively with numerous and diverse manifestations that mimic many diseases (Manger and Gifford 2002).

In a series of patients with PHEO discovered at autopsy, 75\% died suddenly from myocardial infarction or cerebrovascular catastrophe. Approximately one third of these sudden deaths occurred during or immediately after unrelated minor operations (Sutton et al. 1981); therefore, the chosen biochemical test must be reliable in excluding PHEO (Mittendorf et al. 2007).

Main signs and symptoms of catecholamine excess include hypertension, palpitations, headache, sweating, and pallor. Less common signs and symptoms are fatigue, nausea, weight loss, constipation, flush- ing, and fever (Chen et al. 2010). Similar signs and symptoms are produced by numerous other clinical conditions and therefore $\mathrm{PHEO}$ is often referred to as the 'great mimic' (Chen et al. 2010).

The classic triad of ephidrosis (diaphoresis) ${ }^{2}$, palpitations and headache has a reported sensitivity of $89 \%$ and specificity of $67 \%$ for PHEO and in the presence of hypertension $91 \%$ and $94 \%$, respectively (Stein and Black 1991).

Mannelli et al. (1999) conducted a multicentric retrospective study on PHEO in Italy. Data on 284 patients with PHEO observed between 1978 and 1997 were collected from 18 Italian Centers through a questionnaire reporting epidemiological, clinical, laboratory, radiological and surgical data. The presenting symptoms in their study were palpitations (58.1\%), headache $(51.9 \%)$, sweating $(48.8 \%)$, anxiety $(35.3 \%)$, tremors $(25.6 \%)$, nausea $(22.4 \%)$, dyspnea (16.6\%), vertigo (16.5\%), abdominal pain (16.1\%), paresthesia (11.9\%), chest pain (11.8\%), diarrhea/constipation (10.6\%), fainting (5.1\%), and fever (2\%).

\section{Differential diagnosis}

The differential diagnoses of PHEOs according Giannini et al. (1978) include:

1. Anxiety disorders, including benzodiazepine withdrawal syndrome;

2. Extra adrenal paragangliomas;

3. Von Hippel-Lindau Disease;

4. Essential hypertension;

5. Hyperthyroidism;

6. Insulinoma;

7. Mercury poisoning;

8. Paroxysmal supraventricular tachycardia;

9. Renovascular hypertension;

10. Carcinoid.

\section{Inherited syndromes associated with pheochromocytoma}

Up to $25 \%$ of PHEO may be familial (Goldman and Schafer 2012). Several genetic syndromes, all of which are transmitted in an autosomal dominant fashion, are known to be associated with an in-

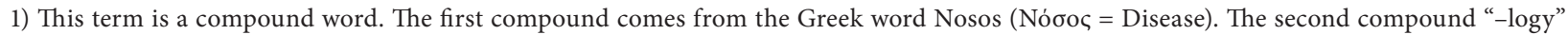

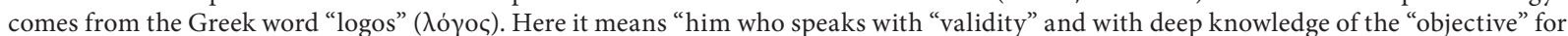
this that it is defined by the first compound word. Nosology is the science of Diseases. In Greek it is used mainly instead of the English term Internal Medicine.

2) Diaphoresis is translated into "sweating" [Dorland Newman WA. Dorland's Illustrated Medical Dictionary, Saunders, 2007]. This is a mis-

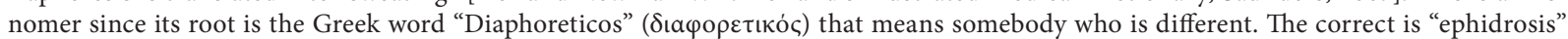
( $\varepsilon \varphi i \delta \rho \omega \sigma \eta \varsigma)$ which in Greek means sweating.
} 
creased risk for PHEO, including von Hippel-Lindau (VHL) syndrome, multiple endocrine neoplasia type 2 (MEN 2), and neurofibromatosis type 1 (NF1) (Inabnet et al. 2000; Pacak et al. 2001a; Bryant et al. 2003). We cite and commend the various syndromes associated with PHEO:

Multiple endocrine neoplasia type 2 (MEN2) is a rare hereditary complex disorder characterized by the presence of medullary thyroid carcinoma (MTC), unilateral or bilateral PHEOs and other hyperplasia and/or neoplasia of different endocrine tissues within a single patient (Marini et al. 2006). Two different forms, sporadic and familial, have been described for MEN2. Sporadic form is represented by a case with two of the principal MEN2 related endocrine tumors, while the familial form, which is more frequent and with an autosomal pattern of inheritance, consists of a MEN2 case with at least one first degree relative showing one of the endocrine characterizing tumors. MEN2 includes three subtypes: MEN2A, MEN2B and familial medullary thyroid carcinoma (FMTC) (Marini et al. 2006). All three subtypes involve high risk for development of MTC; MEN 2A and MEN 2B have an increased risk for PHEOs; MEN 2A has an increased risk for parathyroid adenoma or hyperplasia. Additional features in MEN 2B include mucosal neuromas of the lips and tongue, distinctive faces with enlarged lips, ganglioneuromatosis of the gastrointestinal tract, and a 'marfanoid' habitus. MTC typically occurs in early childhood in MEN 2B, early adulthood in MEN 2A, and middle age in FMTC.

Any individual presenting with a PHEO should be evaluated for von Hippel-Lindau syndrome (VHL) (Erlic and Neumann 2009). VHL syndrome is characterized by PHEO, renal cell carcinoma, cerebellar and spinal hemangioblastoma, and retinal angioma (Erlic and Neumann 2009).

Neurofibromatosis type 1 (NF1) is one of the most common autosomal dominant conditions affecting the nervous system, occurring with an estimated incidence of 1 in 2500 to 3000 individuals independent of ethnicity, race, and gender (Gutmann et al. 1997; Williams et al. 2009). Von Recklinghausen described NF1 in detail in a case report published in 1882 (Reynolds et al. 2003), but because of the varied presentation and pleiotropic nature of the disease, formal diagnostic criteria were not established until 1987 by the National Institutes of Health Consensus Development Conference. Currently, the diagnosis of NF1 is made in an individual with any two of the following clinical features: 1) cafe-au-lait spots; 2) intertriginous freckling; 3) Lisch nodules; 4) neurofibromas; 5) optic pathway gliomas (OPGs); 6) distinctive bony lesions; and 7) a first-degree family relative with NF (Neurofibromatosis 1988; Szudek et al. 2003; Williams et al. 2009).

Medullary thyroid carcinoma (MTC) is a neuroendocrine tumor originating from the parafollicular $\mathrm{C}$ cells of the thyroid gland. It is a calcitonin producing tumor, fact that plays a major role in the diagnosis, as well as in patient's follow up. MTC represents the most challenging disease in thyroid surgery. Even though it is considered an uncommon malignancy, its major clinical and investigational interest relies in its hereditary pattern, and the close correlation with other neuroendocrine disorder, as part of MEN type 2A and 2B syndromes (Prokopakis et al. 2014).

\section{Genetics}

In the past, it was believed that $10 \%$ of PHEOs were associated with MEN2A or MEN2B, VHL, or NF1 (Elder et al. 2003; Harari and Inabnet 2011). Later, this was proven wrong (Elder et al. 2005; Leung et al. 2013). Hereditary cases are usually benign; however, approximately $10 \%$ of PHEOs and $15 \%$ to $35 \%$ of external paragangliomas are malignant (De Toma et al. 2002; Elder et al. 2003; Nakane et al. 2003; PortelaGomes et al. 2004; Harari and Inabnet 2011). Bilateral PHEOs are found in $10 \%$ of sporadic cases, $50-80 \%$ of MEN2 cases, and $40-80 \%$ of VHL cases (Renard et al. 2011).

Recent studies suggest that up to $41 \%$ of patients have a germline mutation in one of the known common susceptibility genes (including NF1, VHL, RET, SDHB, SDHD, SDHC). Despite this, most patients in the United States are not referred for clinical genetic testing by their physicians (Fishbein et al. 2013). Of patients with at least one paraganglia tumor outside the adrenal gland, 53\% had an identified mutation (Fishbein et al. 2013). The most commonly mutated gene was SDHB, which carries the highest risk of malignancy (Fishbein et al. 2013). Identification of a germline mutation on the SDHB gene is a highrisk factor for malignancy and poor prognosis and requires close surveillance of subjects carrying this mutation (Burnichon et al. 2012).

Patients younger than 18 years old who present with PHEO and patients who present with multifocal tumors, extra adrenal tumors, and bilateral tumors are more likely to harbor a genetic predisposition (Neumann et al. 2002; Leung et al. 2013).

The panel at the First International Symposium on Pheochromocytoma recommended that it is neither appropriate nor currently cost-effective to test every disease-causing gene in every patient with a 
pheochromocytoma and paraganglioma (Pacak et al. 2007). Contrary to the above, Fishbein et al. (2013) in their study "Inherited mutations in pheochromocytoma and paraganglioma: why all patients should be offered genetic testing" together with American Society of Clinical Oncology guidelines suggest that genetic testing be performed if the risk of a hereditable mutation is at least $10 \%$ or if it will affect medical management, strongly suggest that all patients with PHEOs/EAP need clinical genetic testing.

\section{Pathology}

It is known that there is no single histologic feature of PHEOs that will consistently predict clinical outcome (Thompson 2002; Maitra 2010). In a large retrospective study of 100 PHEOs (50 benign and 50 malignant) (Thompson 2002), no single histologic feature was able to predict malignancy. Approximately one-fourth of tumors are malignant with metastasis occurring even 20 years after removal of the primary tumor and with only a $50 \%$ five year survival rate (Ayala-Ramirez et al. 2011; Fishbein et al. 2013).

All PHEOs and EAP display similar basic histopathological characteristics although some differences between familial tumors have been described (Chen et al. 2010). Malignant PHEO has a more aggressive course than malignant EAP; long-term survival has not improved over the last two decades. In 2004, the World Health Organization stated that malignant PHEOs are diagnosed only by the documented presence of metastases, and less emphasis was placed on local invasion (IARC 2004; Goffredo et al. 2013). However, in 2007, the Armed Forces Institute of Pathology Fascicle Tumours of the Adrenal Glands and Extra-adrenal Paraganglia defined malignancy as "extensive local invasion or documentation of metastases” (Lack et al. 1997; Goffredo et al. 2013).

Neither tumor size, mitotic rate, nor vascular or capsular invasion is a sufficient discriminating feature with which to distinguish benign from malignant tumors (Sternberg et al. 1999).

Malignant potential is found to be higher in PHEOs with size $>5 \mathrm{~cm}$, EAP and familial cases with mutations of (SDHB) (Ayala-Ramirez et al. 2011; Parenti et al. 2012; Pappachan et al. 2014).

PHEO does not have a standardized staging system. These tumors are grouped clinically into benign (localized), regional, and metastatic. The most common metastatic sites are bones, lungs, liver, and lymph nodes (Lenders et al. 2005). According to the "National Cancer Institute, Surveillance, Epidemiol- ogy, and End Results Program" (NCI SEER) staging system, a tumor is described as local if it is confined entirely to the organ of origin, regional if it extends beyond the primary site to regional lymph nodes (LN) and/or surrounding organs and tissues, and distant if it has metastasized to distant LN or organs (NCI SEER 2015).

\section{Radiology of intra adrenal paragangliomas}

Because of their varied clinical, imaging, and pathologic appearances, accurate diagnosis can be challenging (Leung et al. 2013).

The various imaging appearances on ultrasound, CT, MRI, and functional imaging can be complementary and have features that are useful for differentiating PHEOs from other lesions of the adrenals (Leung et al. 2013). Sporadic PHEO account for most diagnosed cases (Leung et al. 2013). Computed tomography is suggested for initial imaging, but magnetic resonance is a better option in patients with metastatic disease or when radiation exposure must be limited.

\section{Ultrasonography}

Only clinically manifest PHEOs are often already several centimeters in size and can be sonographically detected in $90 \%$ of cases (Hofer 1999).

The PHEO can be localized with ultrasound in $80-90 \%$ of cases (Allolio 2001). PHEO may be visible as a well-defined mass, which may be solid or cystic to variable degrees. Echogenicity will be variable (Conder et al. 2009). On ultrasound, PHEOs have a variable appearance ranging from solid $(75 \%$ in one case series) to mixed cystic and solid to cystic (Bowerman et al. 1981). Gray-scale ultrasound is helpful in confirming cystic-necrotic change within PHEOs. The cystic fluid may be anechoic or contain echogenic debris while posterior acoustic enhancement may be an accompanying feature (Bowerman et al. 1981). Acute hemorrhage in a PHEO may appear echogenic (Bowerman et al. 1981).

\section{Computer tomography (CT)}

PHEOs are often well-defined masses with attenuation values similar to those of muscle tissue, measuring approximately 30-40 HU (Miyake et al. 1989).

On CT, PHEOs may have attenuation values less than $10 \mathrm{HU}$ and also may display more than 60\% washout of contrast agents on delayed scanning. PHEO should be included with adenomas in the dif- 
ferential diagnosis both for masses with low attenuation on unenhanced CT and for lesions exhibiting a high percentage of contrast washout (Blake et al. 2003).

Small neoplasms tend to be solid, whereas large lesions are often cystic or hemorrhagic (Melicow 1977). Non-secreting PHEOs tend to be larger than secreting ones (Newhouse et al. 1999). Cystic degeneration may be so marked that only a thin rim of identifiable cells may remain to disclose the true nature of the lesion. Gross features of PHEOs described in the radiology literature are cystic regions (Melicow 1977), calcifications (Melicow 1977), fibrosis (Melicow 1977), necrosis (Dunnick and Korobkin 2002), and internal hemorrhage (Dunnick and Korobkin 2002).

I.V. administration of non-ionic contrast material for CT is a safe practice for patients with PHEOs and related tumors even without $\alpha$-blocking medication (Bessell-Browne and O’Malley 2007).

\section{Magnetic resonance imaging}

The adrenals can be delineated in nearly all the patients with MRI (Moon et al. 1983; Schultz et al. 1984; Chang et al. 1987; Newhouse 1990; Lee et al. 1998).

An MRI evaluation of the adrenals should usually consist of both T1- and T2-weighted images (Lee et al. 1998). Dynamic serial T1-weighted images obtained after intravenous administration of gadolinium diethylene-triamine penta-acetic acid (Gd-DTPA) are used to show enhancement patterns of adrenal masses (Krestin et al. 1989).

The classic imaging feature for PHEO is a "lightbulb" bright lesion on T2-weighted imaging comparable to the signal intensity of CSF (Elsayes et al. 2004).

Signal intensity within adrenocortical carcinomas and PHEO is significantly higher and heterogeneous on T1 and especially on T2-weighted images, as well as on Diffusion Weighted Imaging. Trace amounts of lipids can occur in adrenal carcinomas, whereas PHEOs almost never contain lipids (Thompson and Young 2003; Ilias et al. 2007; Papierska et al. 2013). PHEOs maintain their signal on opposed-phase gradient-echo images (Elsayes et al. 2005), thus, this technique may help distinguish carcinomas from PHEOs. However, one has to bear in mind that mixed tumors with adrenal cortical and medullary texture, i.e. containing lipids, but also constituting a source of catecholamine excess, were also described (Papierska et al. 2013). MRI should be performed in large tumors prior to surgery to assess vascular invasion (Schteingart et al. 2005).

\section{Functional imaging}

Various substances have been used for functional imaging (FI) of PHEO. FI examinations are performed using ${ }^{131} \mathrm{I}$ - and ${ }^{123} \mathrm{I}$-metaiodobe-nzylguanidine (MIBG), ${ }^{111}$ In-pentetreotide (Octreoscan, Covidien), and several PET ligands including (18)F-fluorodopamine [(18)F-FDA], (18)F-fluorodihydroxyphenylalanine [(18)F-FDOPA], and (18)F-fluoro-2-deoxy-D-glucose [(18)F-FDG], ${ }^{131} \mathrm{I}$ - and ${ }^{123} \mathrm{I}$-metaiodobenzylguanidine $\left[{ }^{131} \mathrm{I} /{ }^{123} \mathrm{I}-\mathrm{MIBG}\right.$ ] (Ilias and Pacak 2004; Havekes et al. 2008; Leung et al. 2013).

Imaging using MIBG is the most common and available technique for functional imaging used in the assessment of PHEO. MIBG is a norepinephrine analog that localizes first to presynaptic adrenergic nerves and sympathomedullary tissue by an active amine transport system and then into cytoplasmic storage vesicles. The uptake of radiotracer is proportional to the number of neurosecretory granules within the tumor (Beierwaltes 1991; Ilias and Pacak 2004; Havekes et al. 2008); therefore, the characteristic appearance of a PHEO is unilateral focal uptake within the tumor (Ilias and Pacak 2004).

Indium 111 pentetreotide is an analog of somatostatin. PHEO can express somatostatin receptors, which allows the use of pentetreotide in the diagnostic process (Leung et al. 2013). These characteristics make PHEO amenable to various FI modalities that, in conjunction with anatomic imaging such as CT and MRI, can assist with the localization and characterization of these unique neoplasms (Jimenez and Waguespack 2015).

Furthermore, in malignant PHEO, (18)F-FDOPA PET, and (18)F-FDA PET were the most successful at identifying lesions not detected via anatomic imaging, providing additional benefit in $6 / 60(10 \%)$ and 5/78 (6.4\%) cases, respectively (Jimenez and Waguespack 2015). No clinically significant findings were observed in any of the predefined subgroups.

Imaging for VHL, NF1 or RET mutations, it is preferred the used of (18)F-FDA or (18)F-FDOPA. In the case of VHL, up to $80 \%$ of PHEOs tends to be bilateral and (18)F-FDA is superior to MIBG due to the low expression of NA membrane transporter in these case (Pacak et al. 2001b; Ilias and Pacak 2004; Havekes et al. 2010; Renard et al. 2011; Megias et al. 2016).

Several PET ligands are currently being developed, some of which are now in use for the diagnostic workup of PHEO. Limitations preventing their widespread use include poor availability and difficult production. At present, most PET ligands are being advantages of PET include higher-resolution images 
and a higher signal-to-noise ratio relative to SPECT (Ilias and Pacak 2004; Havekes et al. 2008; Leung et al. 2013).

In study by Ilias et al. (2003) from Greece, in metastatic disease, (18)F-FDA PET was found to be a superior imaging method in patients with metastatic PHEO, in which correct detection of disease extension often determines the most appropriate therapeutic plan and future follow-up.

PHEOs should always be excluded before attempting fine-needle aspiration biopsy of an adrenal mass, in order to avoid the potential for hypertensive crisis (Incidentaloma 2002). A benign cytological diagnosis on fine-needle aspiration does not, of course, exclude malignancy because of the high false negative rate of this procedure.

\section{Biochemical tests}

Traditionally, 24-h urinary measurement for catecholamines, total and fractionated metanephrines, and vanillylmandelic acid (VMA) has been used to screen patients for PHEO (Mittendorf et al. 2007).

Currently, the diagnosis is established by elevated plasma fractionated metanephrines or elevated 24-h urinary fractionated metanephrines (Lenders et al. 2014; McHenry 2016; Megias et al. 2016). Exception to this are small tumors $(<1 \mathrm{~cm})$, which do not release catecholamines, and the exceptional cases of tumors, which only produce dopamine (van Berkel et al. 2014; Pacak and Wimalawansa 2015; Megias et al. 2016).

Norepinephrine is the predominant catecholamine synthesized by the sympathetic ganglia. Epinephrine is synthesized in the adrenal medulla by $\mathrm{N}$-methylation of norepinephrine, catalyzed by the enzyme phenylethanolamine N-methyltransferase (PNMT), which is restricted to the chromaffin cells of the medulla and induced by cortisol from the cortex (Galati et al. 2015).

Catecholamines continually leak from secretory granules and are inactivated by the enzyme catecholO-methyltransferase (COMT) into free normetanephrine and metanephrine (Schulz et al. 2004). Free normetanephrine and metanephrine circulate in the plasma in low concentrations and have short halflives, undergoing further sulphate conjugation by sulfotransferase isoenzyme (Eisenhofer et al. 2004; Schulz et al. 2004). In contrast to the free metabolites, sulphated metanephrines, are present in 20-40-fold higher concentrations, have a longer half-life, and are eliminated by urinary excretion (Incidentaloma 2002).

Blood sampling should be performed at a supine position after about 15-20 min of i.v. catheter inser- tion. Food, caffeinated beverages, strenuous physical activity, or smoking are not permitted at least about 8-12 h before the testing. Acetaminophen should not be taken for 5 days before the test because it can interfere with the plasma normetanephrine assay (Francis and Korobkin 1996).

The elevation of plasma metanephrines of more than 4 -fold above the upper reference limit is associated with close to $100 \%$ probability of the tumor (Eisenhofer et al. 2003).

Significant metanephrine elevations imply epinephrine excess, which localizes tumors to the adrenal medulla (Galati et al. 2015). Levels of plasma metanephrinesgreaterthan $96 \mathrm{pg} / \mathrm{ml}$, plasmanormetanephrine greater than $130 \mathrm{pg} / \mathrm{ml}$, or total metanephrines greater than 200 are considered abnormal (Francis and Korobkin 1996; Mittendorf et al. 2007).

In patients with plasma metanephrine values above the upper reference limit and less than 4-fold above that limit, the clonidine suppression test combined may prove useful (Eisenhofer et al. 2003). A clonidine suppression test that does not suppress the elevated plasma normetanephrine levels to $<40 \%$ after three hours of administration has a very high sensitivity and specificity (100\% and 96\%, respectively) for diagnosing the tumor in such a situation (Maurea et al. 1996; van Berkel et al. 2014).

Pure dopamine secreting tumors are rare and, therefore, plasma dopamine and its metabolite 3-methoxytyramine are not routinely tested in every case of suspected PHEO/EAP in most laboratories. However, these tests can be useful in some cases, especially metastatic disease, as metastatic tissue lacks the mature enzymes necessary for the synthesis of catecholamines (van Berkel et al. 2014).

Elevated levels of plasma 3-methoxytyramine have been suggested to be a very sensitive marker of malignant tumor when compared to the assays for plasma/ urinary dopamine levels (Eisenhofer et al. 2012; van Berkel et al. 2014).

\section{Preparation for surgery}

Surgical excision is the most effective method for the treatment of PHEOs. PHEO has pathophysiological characteristics of low blood volume and hypertension, and high blood concentrations of catecholamine can lead to catecholamine cardiomyopathy. Therefore, hypertension control and improvement of blood vessel capacity are extremely important for improving surgical safety before surgery (Li and Yang 2014).

The three perioperative phases most associated with hypertensive episodes are endotracheal intuba- 
tion, the creation of pneumoperitoneum, and manipulation of the adrenal gland (Kercher et al. 2005; Bruynzeel et al. 2010; Weingarten et al. 2010; Brunaud et al. 2014). Significant hypotensive episodes also can occur and are associated with a sudden decrease in catecholamine levels after removal of the tumor (Kinney et al. 2002).

Intra-operative risks must be kept to a minimum by appropriate pre-operative medical treatment to block the effects of catecholamines for at least 10-14 days before surgery (Pacak 2007; Pacak et al. 2007). Adequate pre-operative $\alpha$-blockade has been proven to reduce the number of perioperative complications to less than 3\% (Goldstein et al. 1999).

Alpha-blockade is the standard management preoperatively to prevent intraoperative hemodynamic instability during resection of a PHEOs. However these drugs are expensive ( $>1200$ USD for a typical course of preoperative preparation) and hard for patients to obtain at most pharmacies (Siddiqi et al. 2012).

Calcium Channel Blockers (CC-Bs) also have been shown to lessen the risk of intraoperative hemodynamic instability (Brunaud et al. 2014) but it is controversial if one regimen is superior (Brunaud et al. 2014).

Phenoxybenzamine (dibenzyline), is an $\alpha$-adrenoceptor blocker. It is most commonly used for preoperative control of blood pressure. The drug is initially administered orally at a dose of $10-20 \mathrm{mg}$ twice daily. Phenoxybenzamine has a long-lasting action, binding covalently to the alpha receptors. Its only current clinical use is in preparing patients with PHEO for surgery; its irreversible antagonism and the resultant depression in the maximum of the agonist dose-response curve are desirable in a situation where surgical manipulation of the tumor may release a large bolus of pressor amines into the circulation. Typically, phenoxybenzamine is not used in the long term, as new receptors are made to upregulate alpha stimulation. The main limiting side-effects of alpha antagonists is that the baroreceptor reflex is disrupted and thus this can cause postural hypotension (NCI SEER 2015).

Alternatives to phenoxybenzamine for preoperative blockade of catecholamine-induced vasoconstriction include CC-Bs and selective competitive al-adrenoceptor blocking agents, such as terazosin (Hytrin) and doxazosin (Cardura) that have shorter half-lives and lower the risk for postoperative hypotension (Chen et al. 2010).

A $\beta$-adrenoceptor blocker may be used for preoperative control of tachyarrhythmias or angina. However, loss of $\beta$-adrenoceptor-mediated vasodilatation in a patient with unopposed catecholamine-induced vasoconstriction can result in dangerous increases in blood pressure. Therefore, $\beta$-adrenoceptor blockers should never be employed without first blocking $a$-adrenoceptor mediated vasoconstriction.

Volume contraction associated with chronic vasoconstriction can be seen in patients with PHEO and EAP. Therefore, pre-operative volume expansion achieved by saline infusion or increased water intake is recommended to reduce post-operative hypotension (Hack 2000; Chen et al. 2010). Preoperative fluid administration was disputed by some authors (Lentschener et al. 2011).

Hypoglycemia after resection of PHEO is a rare and poorly understood complication thought to be secondary to rebound hyperinsulinemia and increased peripheral glucose uptake. Chen et al. (2014) examined the incidence of this complication and aimed to identify predisposing risk factors. Their data demonstrate that hypoglycemia is a rare complication after resection of PHEOs and may be more common in patients with epinephrine-predominant neoplasms and longer operative times (Chen et al. 2014).

\section{Surgery of pheochromocytoma}

Adrenalectomy is the mainstay of treatment for PHEOs (Press et al. 2014).

Open transperitoneal adrenalectomy has been the gold standard of treatment for adrenal disease (Chai et al. 2014). Other types of adrenal surgery are laparoscopic lateral transperitoneal adrenalectomy (LTA), laparoscopic posterior retroperitoneal adrenalectomy (PRA) and robotic surgery. LTA has been the standard method for resecting benign adrenal gland tumors. Recently, however, PRA has been more popular as an alternative method (Chai et al. 2014).

In a recent paper by Chai et al. (2014) from Korea, in a systematic review they evaluated the current evidence on adrenalectomy techniques, comparing laparoscopic LTA with PRA and laparoscopic adrenalectomy with robotic adrenalectomy. They concluded that PRA was more effective than LTA, especially in reducing operation time and hospital stay, but there was no evidence showing that robotic adrenalectomy was superior to laparoscopic adrenalectomy. Cost reductions and further technical advances are needed for wider application of robotic adrenalectomy (Chai et al. 2014).

As conventional open adrenalectomy offers a wide surgical view and operative field, it is still preferred to laparoscopic adrenalectomy (LA) for large tumors and malignancies (Bittner et al. 2013). 
Hirayama et al. (2015) evaluated the efficacy of LA for PHEOs on the basis of perioperative outcomes. They concluded that LA for PHEO, including large tumors, is safe, feasible, and effective with appropriate perioperative hemodynamic control (Hirayama et al. 2015). The same was concluded by other authors (Jaroszewski et al. 2003; Cheah et al. 2002; Kalady et al. 2004; Kercher et al. 2005; Mezzadri et al. 2010; Sommerey et al. 2015).

Partial adrenalectomy is typically performed for the treatment of hereditary and sporadic bilateral tumors, to reduce the risk of adrenal failure, particularly in younger patients. Partial adrenalectomy proposes a postoperative steroid-free course nevertheless, is associated with the risk of local recurrence. Nagaraja et al. (2015) conducted a systematic review and meta-analysis concerning the "Recurrence and functional outcomes of partial adrenalectomy". They concluded that partial adrenalectomy can obviate the need for steroid replacement in the majority of patients and local recurrence rates appear to be infrequent. Cortical sparing adrenal surgery exhibits $5 \%$ significant recurrence after 10 years of follow-up and normal glucocorticoid function in more than $50 \%$ of the cases (Castinetti et al. 2014). For patients with hereditary and bilateral adrenal tumors, partial adrenalectomy should be recommended as a primary surgical approach whenever possible (Nagaraja et al. 2015).

Recurrence of PHEOs after resection occurs in 6.5-16.5\% of patients (van Heerden et al. 1990; Amar et al. 2005; Shen et al. 2010; Amar et al. 2012; Press et al. 2014) and can be local in the adrenal bed (Brennan and Keiser 1982). Distant recurrences are caused by second primary tumors, such as in the contra lateral gland; metastatic disease, such as in the bone or lung; or gross tumor spillage at the initial operation (Brennan and Keiser 1982). Several hypotheses for recurrent disease exist including failure to identify and completely resect the primary tumor, tumor seeding during needle biopsy or surgery, or the presence of metastases (likely the most common cause) (Tang et al. 2003; Harari and Inabnet 2011).

Recurrence is difficult to treat especially if diagnosis is delayed or disease has metastatic spread (Ellis et al. 2013; Pacak et al. 2007). Therefore, prompt recognition of recurrence is important (Press et al. 2014). In a study by Press et al. (2014), they found that tumor size $>5 \mathrm{~cm}$ was an independent predictor of recurrence and concluded that: Patients with large tumors $(>5 \mathrm{~cm})$ should be followed vigilantly for recurrence. Because $25 \%$ of patients with recurrence had normal biochemical levels, they recommend routine imaging and testing of plasma or urinary metanephrines for prompt diagnosis of recurrence (Press et al. 2014).

If both MTC and PHEO are present in a patient, the PHEO should almost always be removed first (Wells et al. 2015).

\section{Management of advanced disease}

About $10-15 \%$ of PHEOs eventually develop metastases (Pacak and Wimalawansa 2015). Few patients with metastatic PHEOs are suitable candidates for surgical resection of the tumor (Pacak et al. 2001a).

Palliative surgery is usually performed in order to release tumor pressure on surrounding tissues or to decrease tumor mass. Decreased tumor burden can lead to a significant decrease in catecholamine secretion and organ damage as well as alpha and beta blockade dosage. Reduced tumor burden can also facilitate subsequent radiotherapy or chemotherapy. However, a survival advantage of surgical debunking is not proven. In some patients with organ metastatic lesions (not if numerous or very small), radiofrequency ablation or cryoablation are current attractive options (Chen et al. 2010).

Gonias et al. (2009), studied the use of high dose $\left.{ }^{(131} \mathrm{I}\right)$-MIBG therapy for patients with metastatic PHEOs and EAP and found that, although serious toxicity may occur, the survival and response rates achieved with high-dose MIBG suggest its utility in the management of selected patients with metastatic PHEOs/EAP.

Radiofrequency ablation (RFA) is an alternate treatment modality in PHEOs. RFA is a safe, predictable, and effective method for local tumor destruction in primary and metastatic carcinomas (Pacak et al. 2001c). Pacak et al (2001c) used RFA in a patient and commending on their experience they stated that "on the basis of this experience, we propose that RFA be evaluated further in patients with primary or metastatic PHEOs as an alternative to surgery, chemotherapy, or radiotherapy".

6-[(18)F-FDA] positron emission tomography scan provides a valuable tool to evaluate the effects of the ablation; it can be used as an alternative to CT and magnetic resonance imaging, in conjunction with measurements of levels of plasma catecholamines and metanephrines (Pacak et al. 2001b).

\section{Postoperative surveillance}

With regard to surveillance postoperatively, Press et al. (2014) recommend that it is the laboratory values that should be obtained within the first month after 
surgery, again at 6 months, and 1 year, and imaging at 1 year. Laboratory values should be obtained annually, thereafter if everything appears normal (Press et al. 2014). Jaroszewski et al. (2003) recommend longterm follow-up is required for all patients, especially those with hereditary forms of PHEOs.

\section{Discussion}

The clinical presentation of PHEO can be so challenging that gave them the nickname "the great mimicker". The classic triad of presentation of PHEO is palpitations, headaches, and profuse sweating (ephidrosis) but several other symptoms may be present. If PHEO is suspected check for, plasma metanephrines and elevated 24-h urinary fractionated metanephrines. If results are equivocal then proceed with clonidine suppression test. The best imaging test is the CT scan. We may also use MRI especially when we want to avoid radiation or in metastatic diseases. In the event that the diagnosis and/or imaging is equivocal, ( $\left.{ }^{123} \mathrm{I}\right)-\mathrm{MIBG}$ scan can be considered. If the $\left.{ }^{123} \mathrm{I}\right)-\mathrm{MIBG}$ scan is negative and a clinical suspicion still exists, then an FDG-PET scan should be performed (Lenders al. 2014; Galati et al. 2015). The American Society of Clinical Oncology guidelines recommend genetic testing for any patient with over a $10 \%$ prior probability of carrying an inherited cancer susceptibility mutation (ASCO 2003). The patient should receive at least 10-14 days before operation appropriate al-blocker, usually phenoxybenzamine. CC-Bs and or $\beta$-blockers are alternatives or adjunct treatments. Postoperative surveillance constitutes of laboratory values should be obtained within the first month after surgery, again at 6 months, and 1 year, and imaging at 1 year. Laboratory values should be obtained annually thereafter if everything appears normal for the rest of the patients' life.

\section{Acknowledgement}

This research was not supported by any specific grant from public funding agency, commercial or not-for-profit sector.

\section{References}

Adas M, Koc B, Adas G, Yalcin O, Celik S, Kemik O. Pitfalls in the diagnosis of pheochromocytoma: A case series and review of the literature. J Epidemiol Res 2, 49-55, 2016.

Allolio B. Adrenal incidentalomas. In: Adrenal Disorders (Eds. Margioris AN, Chrousos GP), pp 249-261, Humana Press, Totowa, NJ, 2001.

Amar L, Servais A, Gimenez-Roqueplo AP, Zinzindohoue F, Chatellier G, Plouin PF. Year of diagnosis, features at presentation, and risk of recurrence in patients with pheochromocytoma or secreting paraganglioma. J Clin Endocrinol Metab 90, 2110-2116, 2005.

Amar L, Fassnacht M, Gimenez-Roqueplo AP, Januszewicz A, Prejbisz A, Timmers H, Plouin PF. Long-term postoperative follow-up in patients with apparently benign pheochromocytoma and paraganglioma. Horm Metab Res 44, 385-389, 2012.

American Society of Clinical Oncology (ASCO). American Society of Clinical Oncology policy statement update: genetic testing for cancer susceptibility. J Clin Oncol 21, 2397-2406, 2003.

Ayala-Ramirez M, Feng L, Johnson MM, Ejaz S, Habra MA, Rich T, Busaidy N, Cote GJ, Perrier N, Phan A, Patel S, Waguespack S, Jimenez C. Clinical risk factors for malignancy and overall survival in patients with pheochromocytomas and sympathetic paragangliomas: primary tumor size and primary tumor location as prognostic indicators. J Clinl Endocrinol Metab 96, 717-725, 2011.

Beierwaltes WH. Endocrine imaging: parathyroid, adrenal cortex and medulla, and other endocrine tumors. Part II. J Nucl Med 32, 1627-1639, 1991.

Bessell-Browne R, O’Malley ME. CT of pheochromocytoma and paraganglioma: risk of adverse events with i.v. administration of nonionic contrast material. AJR Am J Roentgenol 188, 970-974, 2007.

Bittar DA. Unsuspected phaeochromocytoma. Can Anaesth Soc J 29, 183-184, 1982.

Bittner JG 4th, Gershuni VM, Matthews BD, Moley JF, Brunt LM. Risk factors affecting operative approach, conversion, and morbidity for adrenalectomy: a single-institution series of 402 patients. Surg Endosc 27, 2342-2350, 2013.

Blake MA, Krishnamoorthy SK, Boland GW, Sweeney AT, Pitman MB, Harisinghani M, Mueller PR, Hahn PF. Lowdensity pheochromocytoma on CT: a mimicker of adrenal adenoma. AJR Am J Roentgenol 181, 1663-1668, 2003. 
Bowerman RA, Silver TM, Jaffe MH, Stuck KJ, Hinerman DL. Sonography of adrenal pheochromocytomas. AJR Am J Roentgenol 137, 1227-1231, 1981.

Brennan MF, Keiser HR. Persistent and recurrent pheochromocytoma: the role of surgery. World J Surg 6, 397-401, 1982.

Brunaud L, Boutami M, Nguyen-Thi PL, Finnerty B, Germain A, Weryha G, Fahey TJ 3rd, Mirallie E, Bresler L, Zarnegar R. Both preoperative alpha and calcium channel blockade impact intraoperative hemodynamic stability similarly in the management of pheochromocytoma. Surgery 156, 1410-1418, 2014.

Bruynzeel H, Feelders RA, Groenland TH, van den Meiracker AH, van Eijck CH, Lange JF, de Herder WW, Kazemier G. Risk factors for hemodynamic instability during surgery for pheochromocytoma. J Clin Endocrinol Metab 95, 678-685, 2010.

Bryant J, Farmer J, Kessler LJ, Townsend RR, Nathanson KL. Pheochromocytoma: the expanding genetic differential diagnosis. J Natl Cancer Inst 95, 1196-1204, 2003.

Burnichon N, Abermil N, Buffet A, Favier J, Gimenez-Roqueplo AP. The genetics of paragangliomas. Eur Ann Otorhinolaryngol Head Neck Dis 129, 315-318, 2012.

Castinetti F, Qi XP, Walz MK, Maia AL, Sanso G, Peczkowska M, Hasse-Lazar K et al. Outcomes of adrenal-sparing surgery or total adrenalectomy in phaeochromocytoma associated with multiple endocrine neoplasia type 2: an international retrospective population-based study. Lancet Oncol 15, 648-655, 2014.

Chai YJ, Kwon H, Yu HW, Kim SJ, Choi JY, Lee KE, Youn YK. Systematic review of surgical approaches for adrenal tumors: lateral transperitoneal versus posterior retroperitoneal and laparoscopic versus robotic adrenalectomy. Int J Endocrinol 2014 918346, 2014.

Chang A, Glazer HS, Lee JK, Ling D, Heiken JP. Adrenal gland: MR imaging. Radiology 163, 123-128, 1987.

Cheah WK, Clark OH, Horn JK, Siperstein AE, Duh QY. Laparoscopic adrenalectomy for pheochromocytoma. World J Surgery 26, 1048-1051, 2002.

Chen H, Sippel RS, O’Dorisio MS, Vinik AI, Lloyd RV, Pacak K; North American Neuroendocrine Tumor Society (NANETS). The North American Neuroendocrine Tumor Society consensus guideline for the diagnosis and management of neuroendocrine tumors: pheochromocytoma, paraganglioma, and medullary thyroid cancer. Pancreas 39, 775-783, 2010.

Chen Y, Hodin RA, Pandolfi C, Ruan DT, McKenzie TJ. Hypoglycemia after resection of pheochromocytoma. Surgery 156, 1404-1409, 2014.

Conder G, Rendle J, Kidd S, Misraet RR. A-Z of abdominal radiology. Cambridge University Press, 2009.

De Toma G, Letizia C, Cavallaro G, Giacchino V, Mosiello G, Cavallaro A, Basile U [Malignant pheochromocytoma. Personal experience, review of the literature]. Ann Ital Chir 73, 413-419, 2002.

Dorland Newman WA. Dorland's illustrated medical dictionary. Saunders, Philadelphia, PA, 2007.

Dunnick NR, Korobkin M. Imaging of adrenal incidentalomas: current status. AJR Am J Roentgenol 179, 559-568, 2002.

Eisenhofer G, Goldstein DS, Walther MM, Friberg P, Lenders JW, Keiser HR, Pacak K. Biochemical diagnosis of pheochromocytoma: how to distinguish true-from false-positive test results. J Clin Endocrinol Metab 88, 2656-2666, 2003.

Eisenhofer G, Lenders JW, Pacak K. Biochemical diagnosis of pheochromocytoma. Front Horm Res 31, 76-106, 2004.

Eisenhofer G, Lenders JW, Siegert G, Bornstein SR, Friberg P, Milosevic D, Mannelli M, Linehan WM, Adams K, Timmers HJ, Pacak K. Plasma methoxytyramine: a novel biomarker of metastatic pheochromocytoma and paraganglioma in relation to established risk factors of tumour size, location and SDHB mutation status. Eur J Cancer 48, 1739-1749, 2012.

Elder EE, Skog ALH, Hoog A, Hamberger B. The management of benign and malignant pheochromocytoma and abdominal paraganglioma. Eur J Surg Oncol 29, 278-283, 2003.

Elder EE, Elder G, Larsson C. Pheochromocytoma and functional paraganglioma syndrome: no longer the $10 \%$ tumor. J Surg Oncol 89, 193-201, 2005.

Ellis RJ, Patel D, Prodanov T, Sadowski S, Nilubol N, Adams K, Steinberg SM, Pacak K, Kebebew E. Response after surgical resection of metastatic pheochromocytoma and paraganglioma: can postoperative biochemical remission be predicted? J Am Coll Surg 217, 489-496, 2013.

Elsayes KM, Mukundan G, Narra VR, Lewis JS Jr, Shirkhoda A, Farooki A, Brown JJ. Adrenal masses: MR imaging features with pathologic correlation. Radiographics 24 (Suppl 1), S73-S86, 2004.

Elsayes KM, Narra VR, Leyendecker JR, Francis IR, Lewis JS Jr, Brown JJ. MRI of adrenal and extraadrenal pheochromocytoma. AJR Am J Roentgenol 184, 860-867, 2005.

Erlic Z, Neumann HP. Familial pheochromocytoma. Hormones (Athens) 8, 29-38, 2009. 
Fishbein L, Merrill S, Fraker DL, Cohen DL, Nathanson KL. Inherited mutations in pheochromocytoma and paraganglioma: why all patients should be offered genetic testing. Ann Surg Oncol 20, 1444-1450, 2013.

Francis IR, Korobkin M. Pheochromocytoma. Radiol Clin North Am 34, 1101-1112, 1996.

Galati SJ, Said M, Gospin R, Babic N, Brown K, Geer EB, Kostakoglu L, Krakoff LR, Leibowitz AB, Mehta L, Muller S, Owen RP, Pertsemlidis DS, Wilck E, Xiao GQ, Levine AC, Inabnet WB 3rd. The Mount Sinai clinical pathway for the management of pheochromocytoma. Endocr Pract 21, 368-382, 2015.

Giannini AJB, Henry R, Goettsche, Roger L. Psychiatric, Psychogenic and Somatopsychic Disorders Handbook. M. Examination. Garden City, NY, 1978.

Goffredo P, Sosa JA, Roman SA. Malignant pheochromocytoma and paraganglioma: a population level analysis of long-term survival over two decades. J Surg Oncol 107, 659-664, 2013.

Goldman L, Schafer AI. Goldman's Cecil Medicine E-Book, 24 ${ }^{\text {th }}$ Edition. Elsevier Health Sciences, 2012. https:// www.us.elsevierhealth.com/goldmans-cecil-medicine-e-book-9781437736083.html

Goldstein RE, O’Neill JA Jr, Holcomb GW 3rd, Morgan WM 3rd, Neblett WW 3rd, Oates JA, Brown N, Nadeau J, Smith B, Page DL, Abumrad NN, Scott HW Jr. Clinical experience over 48 years with pheochromocytoma. Ann Surg 229, 755-766, 1999.

Gonias S, Goldsby R, Matthay KK, Hawkins R, Price D, Huberty J, Damon L, Linker C, Sznewajs A, Shiboski S, Fitzgerald P. Phase II study of high-dose [131I] metaiodobenzylguanidine therapy for patients with metastatic pheochromocytoma and paraganglioma. J Clin Oncol 27, 4162-4168, 2009.

Gutmann DH, Aylsworth A, Carey JC, Korf B, Marks J, Pyeritz RE, Rubenstein A, Viskochil D. The diagnostic evaluation and multidisciplinary management of neurofibromatosis 1 and neurofibromatosis 2. Jama 278, 51-57, 1997.

Hack H. The perioperative management of children with phaeochromocytoma. Paediatr Anaesth 10, 463-476, 2000.

Harari A, Inabnet WB 3rd. Malignant pheochromocytoma: a review. Am J Surg 201, 700-708, 2011.

Havekes B, Lai EW, Corssmit EP, Romijn JA, Timmers HJ, Pacak K. Detection and treatment of pheochromocytomas and paragangliomas: current standing of MIBG scintigraphy and future role of PET imaging. Q J Nucl Med Mol Imaging 52, 419-429, 2008.

Havekes B, King K, Lai EW, Romijn JA, Corssmit EP, Pacak K. New imaging approaches to phaeochromocytomas and paragangliomas. Clin Endocrinol (Oxf) 72, 137-145, 2010.

Hirayama T, Fujita T, et al. Safety and feasibility of laparoscopic adrenalectomy for pheochromocytoma irrespective of tumor size. The Kitasato Medical Journal 45, 17-20, 2015.

Hofer M. Kidneys and Adrenal Glands. Ultrasound Teaching Manual Hofer, Matthias, Thieme, 37-50, 1999.

Ilias I, Yu J, Carrasquillo JA, Chen CC, Eisenhofer G, Whatley M, McElroy B, Pacak K. Superiority of 6-[18F]-fluorodopamine positron emission tomography versus [131I]-metaiodobenzylguanidine scintigraphy in the localization of metastatic pheochromocytoma. J Clin Endocrinol Metab 88, 4083-4087, 2003.

Ilias I, Pacak K. Current approaches and recommended algorithm for the diagnostic localization of pheochromocytoma. J Clin Endocrinol Metab 89, 479-491, 2004.

Ilias I, Sahdev A, Reznek RH, Grossman AB, Pacak K. The optimal imaging of adrenal tumours: a comparison of different methods. Endocr Relat Cancer 14, 587-599, 2007.

Inabnet WB, Caragliano P, Pertsemlidis D. Pheochromocytoma: inherited associations, bilaterality, and cortex preservation. Surgery 128, 1007-1012, 2000.

Incidentaloma. NIH state-of-the-science statement on management of the clinically inapparent adrenal mass ("incidentaloma"). NIH Consens State Sci Statements 19, 1-25, 2002.

Jaroszewski DE, Tessier DJ, Schlinkert RT, Grant CS, Thompson GB, van Heerden JA, Farley DR, Smith SL, Hinder RA. Laparoscopic adrenalectomy for pheochromocytoma. Mayo Clinic Proc 78, 1501-1504, 2003.

Jimenez C, Waguespack SG. Functional imaging for pheochromocytoma-paraganglioma: a step closer to understanding its place in clinical practice. Endocrine 50, 6-8, 2015.

Kalady MF, McKinlay R, Olson JA Jr, Pinheiro J, Lagoo S, Park A, Eubanks WS. Laparoscopic adrenalectomy for pheochromocytoma. Surg Endosc 18, 621-625, 2004.

Kercher KW, Novitsky YW, Park A, Matthews BD, Litwin DE, Heniford BT. Laparoscopic curative resection of pheochromocytomas. Ann Surg 241, 916-928, 2005.

Kinney MA, Narr BJ, Warner MA. Perioperative management of pheochromocytoma. J Cardiothorac Vasc Anesth 16, 359-369, 2002.

Krestin GP, Steinbrich W, Friedmann G. Adrenal masses: evaluation with fast gradient-echo MR imaging and GdDTPA-enhanced dynamic studies. Radiology 171, 675-680, 1989. 
Lack EE; Armed Forces Institute of Pathology (US); Universities Associated for Research and Education in Pathology. Tumors of the adrenal gland and extra-adrenal paraganglia. Atlas of Tumor Pathology, Third series. Washington, DC: Armed Forces Institute of Pathology, 1997.

Lee JKT, Sagel SS, Stanley RJ, Heiken JP. Computed body tomography with MRI correlation, Lippincott Williams \& Wilkins, 1998.

Lenders JW, Eisenhofer G, Mannelli M, Pacak K. Phaeochromocytoma. Lancet 366, 665-675, 2005.

Lenders JW, Duh QY, Eisenhofer G, Gimenez-Roqueplo AP, Grebe SK, Murad MH, Naruse M, Pacak K, Young WF Jr; Endocrine Society. Pheochromocytoma and paraganglioma: an endocrine society clinical practice guideline. J Clin Endocrinol Metab 99, 1915-1942, 2014.

Lentschener C, Gaujoux S, Tesniere A, Dousset B. Point of controversy: perioperative care of patients undergoing pheochromocytoma removal-time for a reappraisal? Eur J Endocrinol 165, 365-373, 2011.

Leung K, Stamm M, Raja A, Low G. Pheochromocytoma: the range of appearances on ultrasound, CT, MRI, and functional imaging. AJR Am J Roentgenol 200, 370-378, 2013.

Li J, Yang CH. Improvement of preoperative management in patients with adrenal pheochromocytoma. Int J Clin Exp Med 7, 5541-5546, 2014.

Maitra A. The Endocrine System. In: Robbins and Cotran pathologic basis of disease, professional edition: expert consult (Eds. Kumar V, Abas A, Fausto N, Aster J), pp. 1159-1161, Phladelphia, PA, Saunders Elsevier, 2010.

Manger WM, Gifford RW. Pheochromocytoma. J Clin Hypertens (Greenwich) 4, 62-72, 2002.

Mannelli M, Ianni L, Cilotti A, Conti A. Pheochromocytoma in Italy: a multicentric retrospective study. Eur J Endocrinol 141, 619-624, 1999.

Mantero F, Terzolo M, Arnaldi G, Osella G, Masini AM, Alì A, Giovagnetti M, Opocher G, Angeli A. A survey on adrenal incidentaloma in Italy. Study Group on Adrenal Tumors of the Italian Society of Endocrinology. J Clin Endocrinol Metab 85, 637-644, 2000.

Marini F, Falchetti A, Del Monte F, Carbonell Sala S, Tognarini I, Luzi E, Brandi ML. Multiple endocrine neoplasia type 2. Orphanet J Rare Dis 1, 45, 2006.

Maurea S, Cuocolo A, Reynolds JC, Neumann RD, Salvatore M. Diagnostic imaging in patients with paragangliomas. Computed tomography, magnetic resonance and MIBG scintigraphy comparison. Q J Nucl Med 40, 365-371, 1996.

McHenry CR. Pheochromocytoma: A clinical enigma. Endocr Pract 2016.

Megias MC, Puyol DR, Rodriguez LF, Martinez GLS, Miguel PM. Pheochromocytoma-paraganglioma: Biochemical and genetic diagnosis. [Feocromocitoma-paraganglioma: del diagnostico bioquimico al genetico.] Nefrologia (Madr.) 36, 481-488, 2016.

Melicow MM. One hundred cases of pheochromocytoma (107 tumors) at the Columbia and Presbyterian Medical Center, 1926-1976: a clinicopathological analysis. Cancer 40, 1987-2004, 1977.

Mezzadri NA, Catalina Mandry A, Sinagra DL, Eduardo Falco J, Fernandez Vila JM. [Laparoscopic approach in the treatment of malignant adrenal tumours.] Cir Esp 87, 306-311, 2010.

Mittendorf EA, Evans DB, Lee JE, Perrier ND. Pheochromocytoma: advances in genetics, diagnosis, localization, and treatment. Hematol Oncol Clin North Am 21, 509-525, 2007.

Miyake H, Maeda H, Tashiro M, Suzuki K, Nagatomo H, Aikawa H, Ashizawa A, Iechika S, Moriuchi A. CT of adrenal tumors: frequency and clinical significance of low-attenuation lesions. AJR Am J Roentgenol 152, 1005-1007, 1989.

Moon KL Jr, Hricak H, Crooks LE, Gooding CA, Moss AA, Engelstad BL, Kaufman L. Nuclear magnetic resonance imaging of the adrenal gland: a preliminary report. Radiology 147, 155-160, 1983.

Nagaraja V, Eslick GD, Edirimanne S. Recurrence and functional outcomes of partial adrenalectomy: a systematic review and meta-analysis. Int J Surg 16, 7-13, 2015.

Nakane M, Takahashi S, Sekine I, Fukui I, Koizumi M, Kage K, Ito Y, Aiba K, Horikoshi N, Hatake K, Ishikawa Y, Ogata E. Successful treatment of malignant pheochromocytoma with combination chemotherapy containing anthracycline. Ann Oncol 14, 1449-1450, 2003.

National Cancer Institute, Surveillance, Epidemiology, and End Results Program (NCI SEER). Glossary of Statistical Terms (http://seer.cancer.gov), 2015.

Neumann HP, Bausch B, McWhinney SR, Bender BU, Gimm O, Franke G et al. Germ-line mutations in nonsyndromic pheochromocytoma. N Engl J Med 346, 1459-1466, 2002.

Neurofibromatosis. National Institutes of Health Consensus Development Conference Statement: neurofibromatosis. Bethesda, Md., USA, July 13-15, 1987. Neurofibromatosis 1, 172-178, 1988.

Newhouse JH. MRI of the adrenal gland. Urol Radiol 12, 1-6, 1990. 
Newhouse JH, Heffess CS, Wagner BJ, Imray TJ, Adair CF, Davidson AJ. Large degenerated adrenal adenomas: radiologic-pathologic correlation. Radiology 210, 385-391, 1999.

Pacak K, Linehan WM, Eisenhofer G, Walther MM, Goldstein DS. Recent advances in genetics, diagnosis, localization, and treatment of pheochromocytoma. Ann Intern Med 134, 315-329, 2001a.

Pacak K, Eisenhofer G, Carrasquillo JA, Chen CC, Li ST, Goldstein DS. 6-[18F]fluorodopamine positron emission tomographic (PET) scanning for diagnostic localization of pheochromocytoma. Hypertension 38, 6-8, $2001 \mathrm{~b}$.

Pacak K, Fojo T, Goldstein DS, Eisenhofer G, Walther MM, Linehan WM, Bachenheimer L, Abraham J, Wood BJ. Radiofrequency ablation: a novel approach for treatment of metastatic pheochromocytoma. J Natl Cancer Inst 93, 648-649, 2001c.

Pacak K. Preoperative management of the pheochromocytoma patient. J Clin Endocrinol Metab 92, 4069-4079, 2007.

Pacak K, Eisenhofer G, Ahlman H, Bornstein SR, Gimenez-Roqueplo AP, Grossman AB, Kimura N, Mannelli M, McNicol AM, Tischler AS; International Symposium on Pheochromocytoma. Pheochromocytoma: recommendations for clinical practice from the First International Symposium. October 2005. Nat Clin Pract Endocrinol Metab 3, 92-102, 2007.

Pacak K, Wimalawansa SJ. Pheochromocytoma and paraganglioma. Endocri Pract 21, 406-412, 2015.

Papierska L, Cichocki A, Sankowski AJ, Cwikla JB. Adrenal incidentaloma imaging - the first steps in therapeutic management. Pol J Radiol 78, 47-55, 2013.

Pappachan JM, Raskauskiene D, Sriraman R, Edavalath M, Hanna FW. Diagnosis and management of pheochromocytoma: a practical guide to clinicians. Curr Hypertens Rep 16, 442, 2014.

Parenti G, Zampetti B, Rapizzi E, Ercolino T, Giachè V, Mannelli M. Updated and new perspectives on diagnosis, prognosis, and therapy of malignant pheochromocytoma/paraganglioma. J Oncol 2012, 872713, 2012.

Pederson LC, Lee JE. Pheochromocytoma. Curr Treat Options Oncol 4, 329-337, 2003.

Portela-Gomes GM, Stridsberg M, Grimelius L, Falkmer UG, Falkmer S. Expression of chromogranins A, B, and C (secretogranin II) in human adrenal medulla and in benign and malignant pheochromocytomas An immunohistochemical study with region-specific antibodies. AMPIS 112, 663-673, 2004.

Press D, Akyuz M, Dural C, Aliyev S, Monteiro R, Mino J, Mitchell J, Hamrahian A, Siperstein A, Berber E. Predictors of recurrence in pheochromocytoma. Surgery 156, 1523-1528, 2014.

Prokopakis E, Doulaptsi M, Kaprana A, Velegrakis S, Vlastos Y, Velegrakis G. Treating medullary thyroid carcinoma in a tertiary center. Current trends and review of the literature. Hippokratia 18, 130-134, 2014.

Renard J, Clerici T, Licker M, Triponez F. Pheochromocytoma and abdominal paraganglioma. J Visc Surg 148, e409_ e416, 2011.

Reynolds RM, Browning GG, Nawroz I, Campbell IW. Von Recklinghausen's neurofibromatosis: neurofibromatosis type 1. Lancet 361, 1552-1554, 2003.

Schteingart DE, Doherty GM, Gauger PG, Giordano TJ, Hammer GD, Korobkin M, Worden FP. Management of patients with adrenal cancer: recommendations of an international consensus conference. Endocr Relat Cancer12, 667-680, 2005.

Schultz CL, Haaga JR, Fletcher BD, Alfidi RJ, Schultz MA. Magnetic resonance imaging of the adrenal glands: a comparison with computed tomography. AJR Am J Roentgenol 143, 1235-1240, 1984.

Schulz C, Eisenhofer G, Lehnert H. Principles of catecholamine biosynthesis, metabolism and release. Front Horm Res, 31, 1-25, 2004.

Siddiqi HK, Yang HY, Laird AM, Fox AC, Doherty GM, Miller BS, Gauger PG. Utility of oral nicardipine and magnesium sulfate infusion during preparation and resection of pheochromocytomas. Surgery 152, 1027-1036, 2012.

Sommerey S, Foroghi Y, Chiapponi C, Baumbach SF, Hallfeldt KK, Ladurner R, Gallwas JK. Laparoscopic adrenalectomy--10-year experience at a teaching hospital. Langenbecks Arch Surg 400, 341-347, 2015.

Stein PP, Black HR. A simplified diagnostic approach to pheochromocytoma. A review of the literature and report of one institution's experience. Medicine (Baltimore) 70, 46-66, 1991.

Stenstrom G, Svardsudd K. Pheochromocytoma in Sweden 1958 to 1981. An analysis of the National Cancer Registry Data. Acta Med Scand 220, 225-232, 1986.

Sternberg SS, Antonioli DA, Carter D, Mills SE, Oberman HA. Diagnostic surgical pathology. Philadelphia, PA, USA: Lippincott, Williams \& Wilkins, 1999.

Sutton MG, Sheps SG, Lie JT. Prevalence of clinically unsuspected pheochromocytoma. Review of a 50-year autopsy series. Mayo Clin Proc 56, 354-360, 1981.

Szudek J, Evans DG, Friedman JM. Patterns of associations of clinical features in neurofibromatosis 1 (NF1). Hum Genet 112, 289-297, 2003. 
Tang SH, Chen A, Lee CT, Yu DS, Chang SY, Sun GH. Remote recurrence of malignant pheochromocytoma 14 years after primary operation. J Urol 169, 269, 2003.

The International Agency for Research on Cancer (IARC). Pathology and genetics of tumours of endocrine organs (IARC WHO Classification of Tumours) (Eds. DeLellis RA, Lloyd RV, Heitz P, Eng C). IARC Press, Lyon, 2004.

Thompson LD. Pheochromocytoma of the Adrenal gland Scaled Score (PASS) to separate benign from malignant neoplasms: a clinicopathologic and immunophenotypic study of 100 cases. Am J Surg Pathol 26, 551-566, 2002.

Thompson GB, Young WF Jr. Adrenal incidentaloma. Curr Opin Oncol 15, 84-90, 2003.

van Berkel A, Lenders JW, Timmers HJ. Diagnosis of endocrine disease: Biochemical diagnosis of phaeochromocytoma and paraganglioma. Eur J Endocrinol 170, R109-R119, 2014.

van Heerden J, Roland CF, Carney JA, Sheps SG, Grant CS. Long-term evaluation following resection of apparently benign pheochromocytoma(s)/paraganglioma(s). World J Surg 14, 325-329, 1990.

Weingarten TN, Cata JP, O'Hara JF, Prybilla DJ, Pike TL, Thompson GB, Grant CS, Warner DO, Bravo E, Sprung J. Comparison of two preoperative medical management strategies for laparoscopic resection of pheochromocytoma. Urology 76, 508.e6-508. e11, 2010.

Wells SA Jr, Asa SL, Dralle H, Elisei R, Evans DB, Gagel RF, Lee N, Machens A, Moley JF, Pacini F, Raue F, FrankRaue K, Robinson B, Rosenthal MS, Santoro M, Schlumberger M, Shah M, Waguespack SG; American Thyroid Association Guidelines Task Force on Medullary Thyroid Carcinoma. Revised American Thyroid Association guidelines for the management of medullary thyroid carcinoma. Thyroid 25, 567-610, 2015.

Williams VC, Lucas J, Babcock MA, Gutmann DH, Korf B, Maria BL. Neurofibromatosis type 1 revisited. Pediatrics 123, 124-133, 2009.

Shen WT, Grogan R, Vriens M, Clark OH, Duh QY. One hundred two patients with pheochromocytoma treated at a single institution since the introduction of laparoscopic adrenalectomy. Arch Surg 145, 893-897, 2010 . 